\title{
Cuentos en pie de guerra: caperucitas y patitos feos al servicio de los más diversos ideales. (Adaptaciones de cuentos tradicionales en la Guerra Civil Española.)
}

César Sánchez Ortiz Universidad de Castilla-La Mancha

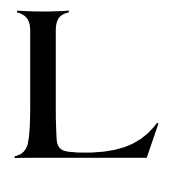

a Literatura Infantil, que no es otra cosa que Literatura dedicada a niños, ${ }^{1}$ y no por ello menos literaria o artística, sino simplemente con unas características propias concretas exigidas por el público a la que va dirigida, - como pueden ser la fantasía, el humor, la repetición, los personajes prototípicos, etc...- comenzó a vivir durante la segunda década del siglo XX y, sobre todo, durante la II República Española, una edad dorada que, como todo, se vio truncada por el radical enfrentamiento entre dos formas distintas de pensar y llevar a cabo la organización política y social del país: los republicanos democráticos y los militares sublevados y más amigos del Antiguo Régimen. La literatura dedicada a niños fue también testigo de estas diferencias y, en sus páginas, nos quedan muestras de aquellos terribles y dispares enfrentamientos tan radicalmente opuestos, a veces para justificar unos y atacar otros, a veces para presentar modelos de conducta con el fin de adoctrinar en las distintas ideologías a los más jóvenes ya desde sus primeras lecturas. Y es que la mayoría de las veces, como se podrá comprobar, los recursos literarios, la buena literatura, quedó relegada a un segundo plano a favor de la exaltación de los distintos ideales y del

${ }^{1}$ CERRILLO, 2001, p. 79-94. 
proselitismo, convirtiéndose los libros de los más pequeños más en armas ideológicas y maniqueístas, que en instrumentos de formación y ocio.

Tras una breve contextualización histórico-cultural que nos sirve para hacernos una idea del ambiente cultural que se respiraba en España en los años previos a la contienda, veremos algunos ejemplos de la utilización de los cuentos populares con los fines mencionados en cada uno de los bandos.

\section{Contexto histórico y artístico}

La época negra más reciente de nuestra historia de España, la contienda civil entre ciudadanos de un mismo país, no fue sino el fatal resultado de una serie de errores que se fueron desencadenando desde unos días antes al terrible 18 de julio de 1936. No es el momento de analizar los antecedentes políticos, el desasosiego social, las críticas personales,... lo cierto, y con ello se puede dar por situado temporalmente este trabajo, es que el mes de julio del 1936 fue testigo de un alzamiento militar contra el gobierno democrático del Frente Popular. Lo que distingue este alzamiento de tantos otros habidos es que a su fracaso inicial - los sublevados pensaban alzarse con el poder en un breve espacio de tiempo - le siguieron una serie de hechos y errores que desencadenaron la cruenta Guerra Civil Española hasta el 1 de abril de 1939, como fueron respectivamente, por ejemplo, la resistencia popular de gran parte del pueblo español y la indeterminación del gobierno a la hora de surtir con armas a las diversas organizaciones obreras que las reclamaban. Así, ninguna de las partes opuestas y enfrentadas en aquel conflicto tuvo desde el principio una fuerza tal que le hiciese merecedora de un dominio total y rápido de la situación. Otra diferencia fue que con el fin del conflicto no se consiguió ningún avance en los distintos ámbitos sociales de la vida del país, sino que siguieron varias décadas de represión, censura y dictadura que sumieron nuestra historia en un retroceso importante, y que, lógicamente, salpicaron también al mundo de la cultura, y más particularmente al de la LIJ.

El panorama cultural y artístico de los prolegómenos de la Guerra Civil se caracteriza por un importante y prometedor avance en todos los campos, muestra de lo cual son las distintas vanguardias que afectan a la arquitectura, escultura, artes plásticas, literatura, etc... y que, como todas las facetas de la vida, quedaron frustradas por el enfrentamiento bélico y los posteriores años de dictadura. Hablar aquí de la ruptura del arte, de la imposición de un 
modelo oficial, del retroceso cultural en general... nos alargaría demasiado, por lo que con esta breve introducción damos por explicado el contexto histórico y cultural, y pasamos a analizar el tema que nos ocupa: la utilización de los cuentos populares con fines ideológicos y propagandísticos. Partimos, para tal tarea, de una búsqueda de dichas obras a través de las fuentes directas clásicas para la localización de libros (BNE, Catálogo Colectivo del Patrimonio Bibliográfico,...), descubriendo que éstas no nos aseguran unos resultados fiables en su totalidad, ya que el gobierno dictatorial resultante de la guerra se encargó de eliminar todo lo que en centros oficiales hubiera de sospechoso o rojo, como ocurre con las obras de Antoniorrobles, un destacado autor de LIJ del que apenas se conserva nada en estos catálogos y que, relacionados con el tema de este encuentro, adaptó a su época y su ideología cuentos clásicos que editó en la Editorial Estrella en los años de la guerra con títulos como El patito feo, Los músicos improvisados, AlíBabá y los cuarenta ladrones, Caperucita Roja, El gato con botas, Pulgarcito y Cenicienta.

\section{Manipulación de cuentos populares}

Partiendo del análisis de algunas adaptaciones de cuentos tradicionales para estos fines bélicos durante la Guerra Civil Española, donde encontramos a personajes tan conocidos como Caperucita Roja, el Patito Feo, Alí Babá, Traganiños,... del lado de los distintos bandos y en las más curiosas circunstancias, intentaremos mostrar la utilización en muchos casos de los cuentos en este determinado periodo histórico como medio y no como literatura ni, por tanto, como fin en sí mismos.

Para ver las características de estas obras en ambos bandos hay que atender a las circunstancias que determinan la vida de la sociedad española en cada uno de ellos, prestando especial atención a las características generales que definen los distintos grupos sociales que constituyen el público lector o, en este caso, el público intermediario entre libros y niños y jóvenes lectores: maestros, padres y, aunque menos, bibliotecarios. Así, en la España republicana la constante que la caracteriza es la heterogeneidad ideológica, que va del liberalismo de los sectores más democráticos al marxismo de socialistas, comunistas y poumistas, pasando por el anarquismo y sindicalismo de cenetistas y el republicanismo llano de la mayoría de la población republicana. El reflejo de esta heterogeneidad 
aparece en los libros, como se puede comprobar en la variedad de editoriales y en las diversas trayectorias bibliográficas de los diferentes autores e ilustradores, que van desde el silencio más prudente de Elena Fortín a las plumas más voraces, como la de Ramón J. Sender, pasando por la mejor literatura de Antoniorrobles, el exilio, el cambio de bando, el cese de la actividad, etc...

Todo lo contrario ocurre en el bando sublevado, organizado en torno a una ideología única y excluyente con un ces, como la de Ramón J. Sender, pasando por la mejor literatura de Antoniorrobles, el exilio, el cambio de bando, el cese de la actividad, etc...

Como se podrá comprobar en el análisis siguiente, ya centrados en los cuentos populares, consecuencia de este alzamiento fue la radicalización ideológica y un despliegue propagandístico sin precedentes, que queda patente en publicaciones, carteles, folletos y revistas, muchos de ellos con el niño como destinatario o, al menos, como protagonista.

\section{Utilización de cuentos populares con fines propagandísticos en el bando republicano: el caso de El patito feo}

Una visión muy somera de la actividad editorial dedicada al público infantil en la zona republicana, con lo que de dinámica e imprecisa tiene esta situación espacio-temporal, nos muestra a Madrid, por poco tiempo, Valencia y, sobre todo, Barcelona como centros creadores y editores. La Generalitat de Cataluña, por ejemplo, dedicó un órgano de su gobierno (Comisariat de Propaganda) a la atención de los libros para niños, con un importante contenido ideológico, pero aceptables literariamente. En este momento propicio para transmitir a través de los libros ideas que, explícita o implícitamente, buscaban crear corrientes de opinión para influir en el pensamiento de los jóvenes lectores, los cuentos populares fueron el instrumento perfecto, pues parten del conocimiento y la simpatía que los más jóvenes sienten hacia ellos.

Como ejemplo de esta circunstancia elegimos, por lo que de representativo tiene y por coincidir este 2005 con el bicentenario del nacimiento del escritor danés H.C. Andersen, la obra de El Patito Feo publicada por la Editorial Estrella en 1937. A través de esta obra, Antoniorrobles nos proporciona un claro ejemplo de lo afirmado, eso sí, 
sin querer en ningún momento engañar al joven lector respecto a la autoría del relato presentándole el cuento como el original de Andersen, sino que subraya claramente que ha sido cambiado de época por él mismo. Sin añadir ni quitar personajes del original, sin alterar la secuencia cronológica de los hechos, Antoniorrobles realiza un cambio considerable de la obra con un fin muy claro: presentar a los niños un ejemplo cercano a ellos y conocido por la mayoría, el Patito Feo, como modelo de niño de clase humilde, luchador, que sin dejarse engañar ni amedrentar por la nobleza ni el fascismo, al final encontrará la victoria sobre todos ellos. Obviando las referencias religiosas con que Andersen escribe su cuento, como la referencia a la casa del cura o del párroco como el lugar más lejano hasta donde llega el mundo de los patos de aquel corral - casa que, curiosamente, Calleja suplanta por la del Alcalde -, y expresiones del tipo "Gracias a Dios" o “iDios mío!", habituales en el escritor danés, Antoniorrobles nos cuenta la obra prácticamente con el mismo argumento y la misma estructura que Andersen, pero con un claro mensaje de lucha por la igualdad de clases y contra el fascismo.

De este modo, los personajes antagonistas son presentados con rasgos peyorativos e identificados con las clases conservadoras más reaccionarias de la sociedad (Estrella, s/p.):

...patos, pavos y gallos se paseaban con desagradable orgullo, considerándose cada uno lo mejor de su casta. Eran, en fin, como esos condes y duques que presumen porque vienen de condes y duques antiguos. ...sacrificarse por sus hijos la cansaba bastante, lo cual ha sido siempre cosa de señoras muy distinguidas, que, aun no teniendo nada que hacer, mandan a los hijos a pasear con las ayas,...

...le consideraba demasiado silvestre y vulgar. ¿Para qué educar a un pato que parecía, como si dijéramos, hijo de un obrero, y no del conde de Aguas-Verdes?

Los jóvenes patos de la granja eras unos estupidillos "pollos-peras" (...). Todos andaban con mucha presunción, y se saludaban extendiendo un ala, porque decían que eso era a la manera fascista. Y no hacían nada en todo el día, como buenos señoritos, $\ldots$

... el pato español, llamado duque del Alba, le dijo un día:

- (...) Tiene aire de campesino sin raza; parece hijo de unos trabajadores cualesquiera.

Y ante tal ambiente creado por tales personajes, al igual que en el cuento original, cansado de la marginación y la incomprensión, el patito feo sale a buscar una nueva vida (Estrella, s/p.): 
Prefirió lanzarse a luchar en la vida por sí mismo, que no sufrir los desprecios de aquellos patos y pavos fascistas, que no tenían más preocupaciones que la de ser elegantes y comer sin trabajar.

Y es a partir de entonces, con el patito vagando por los mismos lugares que en el original danés, cuando Antoniorrobles comienza a proclamar por pico del protagonista los ideales republicanos que quiere transmitir a todos los lectores, unos ideales a favor de la igualdad, la cultura y la educación de todas las clases (Estrella, s/p.):

- ¡Qué lástima me dan estos patos incivilizados! Si los patos de clase elevada se ocupasen de civilizar a los demás, habría más armonía en lagos y pantanos; pero los patos ilustres se cuidan de apartarse de los silvestres y de no darles cultura, para que se vea que aún hay clases entre unos y otros. Afortunadamente, día llegará en que los patos silvestres se encargarán de civilizarse por sí mismos.

O cuando al ver pasar los cisnes exclama (Estrella, s/p.):

...se adivinaba que era un grupo de aves selectas, como de profesores que iban por el mundo enseñando a los humildes que debieran unirse y ser todos felices en paz, sin la antipatía de los patos privilegiados ni la existencia de patos incultos y silvestres. Ésas eran las doctrinas de aquellos cisnes que tanto emocionaron al patito feo al pasar sobre el lago.

Y como colofón del alegato de Antoniorrobles por el ideal que ha venido defendiendo, sirva uno de los últimos párrafos del cuento (Estrella, s/p.):

¡Qué año de verse despreciado, cuando aquellos patos orgullosos y fascistas de la granja le creían un pato silvestre y vulgar!... Ahora verían todos con envidia que se puede ser de joven una modesta ave parda y llegar luego a ser un magnífico cisne que, como aquellos otros tres del lago, se dedicó mansamente y sin vanidad a predicar la unión de los patos y las aves acuáticas del mundo, para que no hubiera razas fascistas como las de la granja, que despreciaban todo lo que tuviera aspecto de aves trabajadoras y humildes. 


\section{Utilización de cuentos populares con fines propagandísticos en el bando sublevado: el caso de Caperucita encarnada}

Hablar de LIJ en el bando sublevado viene a ser prácticamente sinónimo de LIJ de posguerra, ya que hasta los años finales de la contienda, salvo raras excepciones, no encontramos una labor coordinada y decidida en la creación y edición de literatura para niños. Posiblemente por el hecho de centrar todos sus esfuerzos en el campo militar, la labor editorial en esta zona no contó al principio de la contienda con una planificación como la llevada a cabo por distintos organismos oficiales de la II República, caracterizándose más por la dispersión de diferentes y escasas iniciativas privadas de baja calidad literaria, como es el caso de El imperio de los enanitos de Casimiro Diz Lois. Y es que la mayoría de los cuentos para niños se canalizaron a través de las revistas infantiles, como la oficial Flechas y Pelayos, fruto de la unión de dos revistas anteriores y resultado de la unificación impuesta por el sistema totalitario del General Franco. La línea ideológica y editorial de estas publicaciones queda patente en este fragmento con que se abría la edición del primer número de la mencionada publicación oficial en 1939:

Aquí tenéis un periódico que os enseñará a cumplir con vuestro deber de pequeños soldados de la FALANGE y de España, y que sabrá, también, divertiros (...). Flechas os saluda hoy, con el brazo en alto con el saludo que todos vosotros debéis hacer constantemente, en la calle, en la escuela, en el paseo, al ver a los Jefes (...). Tenéis que llevar siempre la camisa azul y pensar que el fusil y el libro son los más grandes regalos que puedan hacérsele a un español.

Y en lo referente al tema que nos ocupa, de nuevo los cuentos populares vuelven a ser mal utilizados con fines ideológicos. Además, en los localizados en este bando no sólo hay que resaltar este hecho, sino también una fuerte influencia eclesiástica que conllevó a la identificación o buena relación del protagonista con personajes divinos y religiosos, y la de los antagonistas con duendes, enanos y demonios.

Entre estos cuentos populares elegimos como ejemplo una versión de la popular Caperucita Roja adaptada al teatro, género de escasa importancia en el mundo editorial infantil en esta época, del que tan sólo encontramos alguna versión dedicada al uso escolar, como la que aquí nos ocupa. 
Editada en Cáceres a finales de la Guerra Civil, el mismo título nos indica el contenido con el que nos vamos a encontrar al leer la obra: Caperucita Encarnada. Nueva versión del célebre cuento dialogado y puesto en escena por la regidora comarcal de prensa y propaganda de Trujillo, camarada Mercedes Terrones Durán.

La historia, conocida por todos, es adornada con canciones populares (Caperucita comienza cantando "Estaba la pájara pinta,...") y una serie de nuevos personajes: un hada buena, a imagen de una Virgen, que encarna el bien; un enano diabólico que intenta y consigue engañar a la niña para que no obedezca a la mamá ni al hada y vaya por el camino más largo; y un lobo, encarnación del mal, amo de todos los enanos, que se come a la abuela y a la niña y acaba desollado por el cazador.

Hasta aquí, aún con estas alteraciones, pudiera ser más o menos aceptable por tratarse de una escenificación en la que probablemente habría que dar cabida a muchos niños para que todos participasen. Pero, como el ya mencionado cambio de título apuntaba, el sustrato ideológico del relato es la principal característica del mismo como ejemplo de manipulación de la LIJ en este bando a favor de la ideología oficial y religiosa del momento.

Cuando el enano la anima a desobedecer a su madre e ir por el camino más largo, Caperucita le responde:

A las niñas que son desobedientes les ocurren muchas desgracias. Y luego cuando mueren, en lugar de ir al Cielo con la Virgen que es tan guapa y tan buena y a jugar con el niño Jesús, ise las lleva el demonio al infierno, donde no hay más diablillos feos y negros que las pinchan!

Cuando el cazador rescata del vientre del lobo a la abuela y a la nieta, la abuela le da las gracias, pero el cazador las rechaza argumentando:

¡Gracias a Dios, señora Micaela! Todas las cosas buenas que nos ocurren a Él se las debemos y únicamente cuando no cumplimos con su Ley nos suceden desgracias.

$Y$ al final, cuando incluso el enano se arrepiente de haberla engañado para que fuese por el camino, el Hada buena sorprende a todos con la siguiente intervención:

Bueno, Caperucita, te repito lo dicho. ¡Hasta la vista! Pero antes de separarme de ti, voy a darte un recuerdo. (Saca de entre su ropa una caperuza igual a la que lucía la niña en el primer acto, pero azul en lugar 
de encarnada, y se la da a la niña). Toma, he visto que perdiste tu caperuza, ahí tienes otra para sustituirla.

Y, tras las gracias de Caperucita y su reflexión sobre el cambio de nombre que ahora tendrá que hacerse por su nueva vestimenta, el Hada le confirma:

Efectivamente. Te llamarán "Caperucita Azul". Y no olvides que el azul significa obediencia, disciplina, sacrificio... amor en fin.

\section{Conclusiones}

De las dos obras analizadas con más atención, podemos concluir que la finalidad moralizante de la LIJ, materia en la que se enmarcan los cuentos populares, es una característica (más o menos perjudicial) presente desde sus principios, ya que "la fascinación que producen los textos literarios entre los más jóvenes favorece la transmisión de determinados valores”, ${ }^{2}$ y más presente aún en situaciones extremas como es el caso que nos ocupa. En esta misma línea, Felicidad Orquín afirma que "la literatura tiene un extraordinario poder de sugestión y todo gran lector sabe en qué medida los personajes de ficción han conformado su propia vida, su manera de sentir y de pensar. (...) Esta fascinación de la literatura se acentúa cuando es un lector joven quien se enfrenta a lo imaginario." ${ }^{3}$ Lo que ocurre en el caso de los cuentos populares en la Guerra Civil es que este discurso moral o costumbrista, reflejo en la mayoría de los casos de la sociedad en que se vive, se lleva a tal extremo que conduce a redacciones e ilustraciones rupturistas y extremadamente maniqueas, propiciando así el clima bélico y la radicalización de las posturas, pues el lector desde el primer momento capta la intencionalidad moralizante del autor, mientras que en el resto de las obras, como en las actuales, este discurso prácticamente no es apreciado.

En resumen, y como se ha visto a lo largo de estas páginas, el proselitismo y la expansión de las respectivas ideologías son también característicos de las distintas versiones de los cuentos populares editados durante este periodo, quedando la auténtica literatura y los recursos

\footnotetext{
${ }^{1}$ ETXANIZ, 2004, p. 83.

2 ORQUín, 1989, p. 15.
} 
literarios un poco fuera de la órbita de estas ediciones, sobre todo de las del bando sublevado, como seguirá ocurriendo años después durante la posguerra.

Pero no todo tiene porqué ser negativo, y partiendo de esta experiencia podemos quedarnos con la conclusión de que estos cuentos tienen un valor tal que hoy se siguen transmitiendo de boca en boca en diversas versiones, tras haber sido manipulados con las peores intenciones, ya que son transmisores de valores universales sin necesidad de enseñar, necesariamente, algo. Es tal el valor de estos cuentos e historias que, a pesar de las muchas adaptaciones y manipulaciones, por lo general siguen fieles a su esquema tradicional. Y por eso se puede y debe seguir trabajando con este universo narrativo popular, eso sí, respetando en todo momento la esencia del cuento, su trama argumentativa, sus personajes y su secuencia cronológica...

\section{Referências}

CERRILLO, Pedro C. Lo literario y lo infantil: concepto y caracterización de la Literatura Infantil. En CERRILLO, P. C. y GARCÍA PADRINO, J. La Literatura Infantil en el siglo XXI. Cuenca: Ediciones de la UCLM, 2001, p. 79-94.

ETXANIZ, Xavier. La ideología en la LIJ. En CAUCE, Revista de Filología y su Didáctica, n. 27, p.83, 2004.

ORQUín, Felicidad. La nueva imagen de la mujer, en CLIJ n. 11, p. 15, 1989. 


\section{Resumen}

La Literatura Infantil en España comenzó a vivir durante el siglo XX y, sobre todo, durante la II República, una edad dorada que, como toda la vida española en sus más diferentes ámbitos, se vio truncada por el radical enfrentamiento entre dos formas distintas de pensar y llevar a cabo la organización social y política del país: los republicanos y los franquistas. La LIJ fue también testigo de esas diferencias; en sus páginas nos quedan muestras de aquellos enfrentamientos, presentes en ediciones de cuentos tradicionales utilizadas con los más diversos fines: a veces para justificar unos y atacar otros, a veces para justificar modelos de conducta con el fin de adoctrinar en las distintas ideologías a los más jóvenes ya desde sus primeras lecturas. Lo cierto es que la mayoría de las veces la buena literatura quedó relegada a un segundo plano a favor de la exaltación de los distintos ideales y del proselitismo partidista.

Partiendo del análisis de algunas adaptaciones de cuentos tradicionales para estos fines bélicos durante la Guerra Civil Española, donde encontramos a personajes tan conocidos como Caperucita Roja, el Patito Feo, Alí Babá, Traganiños,... del lado de los distintos bandos y en las más curiosas circunstancias, se intenta mostrar la utilización en muchos casos de los cuentos en este determinado periodo histórico como medio y no como literatura ni, por tanto, como fin en sí mismos.

\section{Resumo}

Na Espanha, a literatura infantil nasce no século XX, sobretudo, durante a II República, idade dourada que, como toda a vida espanhola em suas diversas esferas, se viu cindida pelo radical enfrentamento entre duas formas distintas de pensar a organização social e política do país: os republicanos e os franquistas. A literatura infanto-juvenil foi também testemunho dessas diferenças; em suas páginas surgem amostras daqueles enfrentamentos, presentes nas edições de contos tradicionais utilizados com os mais diversos fins: às vezes para justificar uns e atacar outros, às vezes para justificar modelos de conduta com o fim de doutrinar os mais jovens desde suas primeiras leituras.

O certo é que na maioria das vezes a boa literatura foi relegada a um segundo plano, em favor da exaltação de distintos ideais e do proselitismo partidário. Partindo da análise de algumas adaptações de contos tradicionais para fins bélicos durante a Guerra Civil Espanhola, em que encontramos personagens tão conhecidas como Chapeuzinho Vermelho, Patinho Feio, Ali Babá, Bicho Papão, junto aos diferentes partidos e nas mais curiosas circunstâncias, pretende-se mostrar a utilização, em muitos casos, dos contos neste determinado período histórico como meio e não como literatura nem, portanto, como fim em si mesmos. 